\title{
AEROMAGNETIC MAP OF THE THOMPSON FALLS QUADRANGLE LINCOLN AND SANDERS COUNTIES, MONTANA
}

\author{
GEOPHYSICAL INVESTIGATIONS \\ MAP GP-686
}

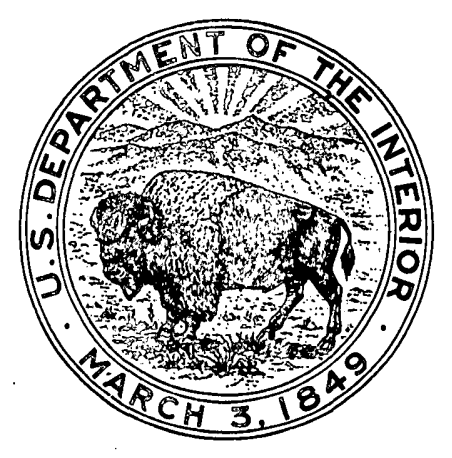

PUBLISHED BY THE U. S. GEOLOGICAL SURVEY

WASHINGTON. D.C. 